\title{
Results from Sweden's 2018 Report Card on Physical Activity for Children and Youth
}

\author{
Christine Delisle Nyström, Christel Larsson, Christina Alexandrou, Bettina Ehrenblad, \\ Ulf Eriksson, Marita Friberg, Maria Hagströmer, Anna Karin Lindroos, Gisela Nyberg, and Marie Löf
}

\section{Introduction}

In children and youth there are numerous studies showing the associations between low levels of physical activity and high amounts of sedentary time with reduced physical and mental health. Therefore, the consolidation of physical activity and sedentary behavior data is important, in order for researchers, policy makers, and key stakeholders to identify problem areas and intervene appropriately. Thus, the aim of this paper is to summarize the results of Sweden's 2018 Report Card on Physical Activity for Children and Youth.

\section{Methods}

Sweden's 2018 Report Card included the ten core physical activity indicators that are common to the Global Matrix 3.0, which are: overall physical activity, organized sport participation, active play, active transportation, sedentary behaviors, physical fitness, family and peers, school, community and environment, and government. Additionally, an indicator for diet was also included. Each of the 11 indicators were assigned a grade ranging from $\mathrm{F}$ to $\mathrm{A}+$ representing the percentage of children and youth meeting a defined benchmark. If there was no data or insufficient data for an indicator it was marked as incomplete.

Data from a multitude of sources from 2013 to 2018 were compiled in order to inform the grades for the 11 indicators. Where possible, results from national surveys were used to inform the grades (e.g., The Health Behaviour in School-aged Children (HSBC) 2013-14, ${ }^{1}$ Children's Routes to School Survey 201516, ${ }^{2}$ Living Conditions Survey of Children 2015-16, ${ }^{3}$ and The National Dietary Survey 2016-174). Where no national data was available peer reviewed literature and gray literature (e.g., governmental reports) were utilized.

\section{Results and Discussion}

Sweden's 2018 Report Card on physical activity for children and youth builds on the findings from Sweden's 2016 Report Card. ${ }^{5}$ The results are summarized in Table 1 and the 2018 Swedish Report Card's front cover is displayed in Figure 1.
Three of the 11 indicators, i.e., active play, family and peers, and physical fitness were assigned a grade of incomplete due to the lack of available data for these indicators, thus showing that knowledge and research gaps exist. Even though the grades were based on the best available evidence some limitations need to be acknowledged. For overall physical activity there was no national level data available. However, for the next report card national objectively measured physical activity data will be available, as it is currently being analyzed. Therefore, for this Report Card individual studies reporting the number of children meeting the overall physical activity benchmark were used. The additional indicator, diet was

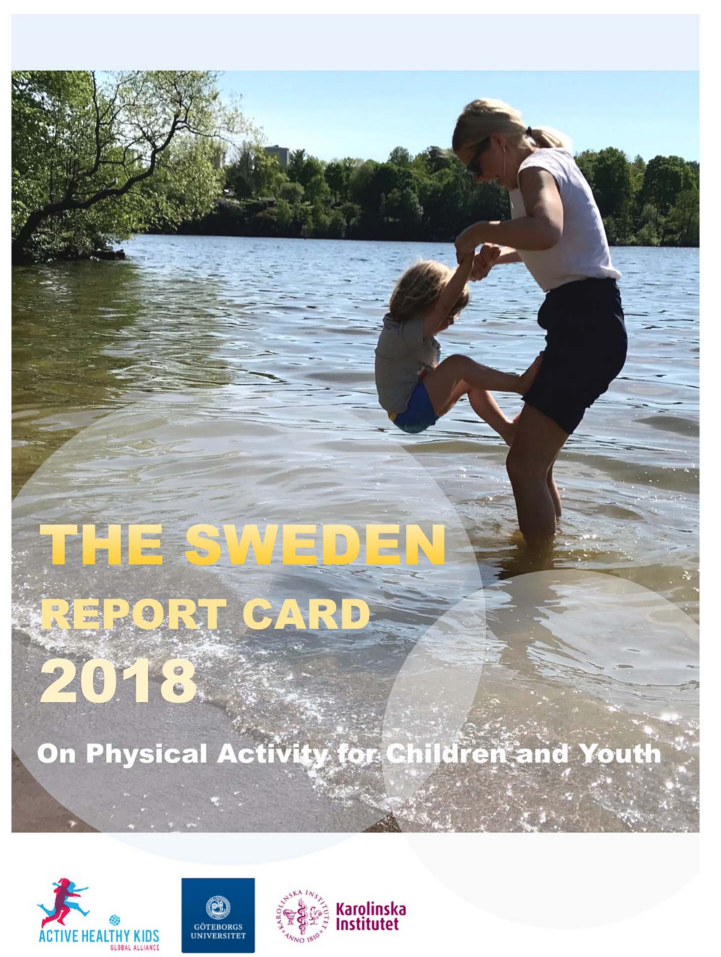

Figure 1 - Sweden's 2018 Report Card cover.

Delisle Nyström is with the Department of Biosciences and Nutrition, Karolinska Insitutet, Huddinge, Sweden and the Healthy Living and Obesity Research Group, Children's Hospital of Eastern Ontario, Ottawa, Ontario, Canada. Larsson is with the Department of Food and Nutrition and Sport Science, University of Gothenburg, Gothenburg, Sweden. Alexandrou and Ehrenblad are with the Department of Biosciences and Nutrition, Karolinska Institutet, Huddinge, Sweden. Eriksson is with Kosterhavets Ekobod AB, Nordkoster, Sweden. Friberg is with the Public Health Agency, Sweden. Hagströmer is with the Department of Neurobiology, Care Sciences, and Society, Karolinska Institutet, Huddinge, Sweden. Lindroos is with The National Food Agency, Sweden. Nyberg is with the Department of Public Health Sciences, Karolinska Institutet, Stockholm, Sweden. Löf is with the Department of Biosciences and Nutrition, Karolinska Institutet, Huddinge, Sweden and the Department of Medical and Health Sciences, Linköping University, Linköping, Sweden. Löf (marie.lof@ki.se) is the corresponding author. 
Table 1 Grades and rationales for Sweden's 2016 Report Card

\begin{tabular}{|c|c|c|}
\hline Indicator & Grade & Rationale \\
\hline $\begin{array}{l}\text { Overall Physical } \\
\text { Activity }\end{array}$ & $\mathrm{D}+$ & $\begin{array}{l}18 \% \text { of girls and } 43 \% \text { of boys aged } 6-11 \text { years accumulate } \geq 60 \mathrm{~min} \text { of MVPA/day on average. }{ }^{6} \\
33 \% \text { of girls and } 46 \% \text { of boys aged } 13-15 \text { years accumulate } \geq 60 \mathrm{~min} \text { of MVPA/day on average. }{ }^{7}\end{array}$ \\
\hline $\begin{array}{l}\text { Organized Sport } \\
\text { Participation }\end{array}$ & $\mathrm{B}+$ & $75 \%$ of $11-15$ year olds participate in organized sport $\geq 2$ times/week. ${ }^{1}$ \\
\hline Active Play & INC & Insufficient data to grade this indicator. \\
\hline Active Transportation & $\mathrm{C}$ & $\begin{array}{l}48 \% \text { and } 57 \% \text { of } 6-15 \text { year olds use active transportation to and from school in the winter and summer months, } \\
\text { respectively. }\end{array}$ \\
\hline Sedentary Behaviors & $\mathrm{C}+$ & $\begin{array}{l}55 \% \text { of } 6 \text { year olds had }<2 \text { hrs of screen time/day on average. }{ }^{8} \\
60.5 \% \text { of } 6-9 \text { year olds had }<2 \mathrm{hrs} \text { of screen/day on average. } \\
71 \% \text { and } 49 \% \text { of girls and boys aged } 6-11 \text { years had }<2 \text { hrs of screen time/day on average. }{ }^{6} \\
62 \% \text { of } 11-15 \text { year olds had }<2 \text { hrs of screen time on an average day. }{ }^{1}\end{array}$ \\
\hline Physical Fitness & INC & Insufficient data to grade this indicator. \\
\hline Family and Peers & INC & Insufficient data to grade this indicator. \\
\hline School & $\mathrm{C}+$ & $\begin{array}{l}\text { The Education Act includes after school childcare and emphasizes the promotion of a healthy lifestyle. } \\
\text { Physical education is mandatory in primary/secondary school (min of } 90 \text { and } 115 \mathrm{~min} / \mathrm{week} \text {, respectively). }\end{array}$ \\
\hline $\begin{array}{l}\text { Community and } \\
\text { Environment }\end{array}$ & A & $\begin{array}{l}94-100 \% \text { of } 0 \text { to } 15 \text { year olds living in urban areas ( } \min 30000 \text { inhabitants) have access to greenspace within } \\
300 \text { meters of their house. }{ }^{10} \\
99 \% \text { and } 88 \% \text { of } 12-18 \text { year olds report feeling safe or quite safe outside where they live during the daytime and } \\
\text { nighttime, respectively. }\end{array}$ \\
\hline Government & B & $\begin{array}{l}\text { Physical activity is one of the } 11 \text { objective domains for the national public health policy. } \\
\text { The transportation and urban planning agencies have policies and guidelines addressing physical activity and a } \\
\text { national cycling strategy for increased and safe cycling has recently been put forward. }\end{array}$ \\
\hline
\end{tabular}

given a grade of "C" as less than $20 \%$ of $11-18$ year olds consumed $\geq 500 \mathrm{~g}$ of fruits and vegetables each day; $60-70 \%$ of $11-18$ year olds ate fish $\geq 1$ time/week; and $64-76 \%$ of $11-18$ year olds consumed sugar sweetened beverages $\leq 1$ time/week. ${ }^{4}$

As the relatively low grades for the 2018 Report Card have remained virtually unchanged since 2016 for daily behavior indicators such as overall physical activity, sedentary behavior, and active transportation it is vital that key stakeholders begin to plan how to appropriately intervene in order to increase overall physical activity and decrease sedentary time in Swedish children and youth.

\section{Conclusion}

In Sweden the community and the built environment favor an active lifestyle and the promotion of physical activity. Furthermore, there are strong government initiatives that promote physical activity among children and youth. Despite the conducive environment for physical activity in Sweden, overall physical activity is low and sedentary behavior is high, which indicates a need for a more integrated approach to promote physical activity in Sweden's children and youth.

\section{References}

1. The Public Health Agency of Sweden. The Health Behaviour in School-aged Children in Sweden. Stockholm, Sweden; 2013-2014.

2. Swedish Transport Administration. Children's routes to school, TRV 2013/54076. Borlänge, Sweden; 2015.
3. Statistics Sweden. Living conditions survey of children 2015-2016. http://www.scb.se/en_/Finding-statistics/Statistics-by-subject-area/ Living-conditions/Living-conditions/Living-Conditions-Survey-ofChildren/. Accessed May 29, 2018.

4. The National Food Agency of Sweden. The National Dietary Survey Intake of Foods and Nutrients in Swedish Children. Uppsala, Sweden; 2016-2017.

5. Nystrom CD, Larsson C, Ehrenblad B, et al. Results from Sweden's 2016 report card on physical activity for children and youth. $J$ Phys Act Health. 2016;13(11 suppl 2):S284-S290.

6. Kovacs E, Siani A, Konstabel K, et al. Adherence to the obesityrelated lifestyle intervention targets in the IDEFICS study. Int J Obes. 2014;38(suppl 2):S144-S151.

7. Johansson H, Norlander K, Janson C, Malinovschi A, Nordang L, Emtner M. The relationship between exercise induced bronchial obstruction and health related quality of life in female and male adolescents from a general population. BMC Pulm Med. 2016;16(1):63.

8. Beckvid Henriksson G, Franzen S, Elinder LS, Nyberg G. Low socioeconomic status associated with unhealthy weight in six-year-old Swedish children despite higher levels of physical activity. Acta Paediatr. 2016;105(10):1204-1210.

9. Wijnhoven TM, van Raaij JM, Yngve A, et al. WHO European Childhood Obesity Surveillance Initiative: health-risk behaviours on nutrition and physical activity in 6-9-year-old schoolchildren. Public Health Nutr. 2015;18(17):3108-3124.

10. Statistics Sweden. Data on greenspace from 2010. http://www. statistikdatabasen.scb.se/pxweb/sv/ssd/START__MI__MI0805 MI0805B/GronOmrBef300M/?rxid=828974bb-aab6-4375-83540594330cad9e. Accessed May 29, 2018. 